\title{
MODIFICATION OF ALUMINIUM-SILICON NEAR-EUTECTIC ALLOY WITH USE OF ELECTROLYSIS OF SODIUM SALT
}

\begin{abstract}
The present work discusses results of preliminary tests concerning the technology of continuous dosage of sodium to a metallic bath from the aspect of modification of EN AC-44200 alloy, through the use of a multiple compound (salt) of sodium. The technology consists in continuous electrolysis of sodium salts occurring directly in a crucible with liquid alloy. As a measure of the degree of alloy modification over the course of testing, the ultimate tensile strength (UTS or Rm) and analysis of microstructure are taken, which confirm the obtained effects of the modification on the investigated alloy. Assurance of stable parameters during the process of continuous modification with sodium, taking into consideration the fact of complex physical-chemical phenomena, requires additional tests aimed at their optimization and determination of a possibility of implementation of such technology in metallurgical processes.

Keywords: Al-Si alloys, electrolysis, tensile strength, microstructure
\end{abstract}

\section{Introduction}

Development of a modern technologies results in a supply of more better, more robust engineering materials, assuring the mechanical properties to be previously unreachable. Their weight is of non-negligible importance in the case of metallic structures, and hence, the mass of materials used in a given structure. Lightweight metals and their alloys are more often applied in metallic structures, among them, the most common are aluminum and its alloys. The properties of aluminum that make this metal and its alloys the most economical and attractive for a wide variety of uses are their appearance, light weight, fabricability, physical properties, mechanical properties, and corrosion resistance [1]. Pure aluminum is used very seldom; the most often used in foundry industry are Al-Si alloys with hypoeutectic and near-eutectic contents of silicone (about 12,5wt.\%) with alloying additions. One of a few disadvantages is their eutectic structure, which is characterized by a coarse-grained silicone that has an adverse effect on the mechanical properties of the material. To improve the mechanical properties of casting alloys based on Al-Si system, one commonly uses modification of the eutectic mixture. Process of the modification consists in the addition of modifiers, such as e.g. $\mathrm{Na}, \mathrm{Sr}, \mathrm{Sb}, \mathrm{Ca}$ (chemical modification) or though rapid cooling rates (quench modification) to the changed structure of eutectic Si, from lamellar to fibrous and spherical [2-8].

Sodium belongs to the common metal implemented in the industry and the most effective modifiers. The sodium is introduced to a metal bath in its metallic form or as a chemical compound containing sodium. However, regardless of the form in which the modifier is introduced to metal bath, its action is relatively short (about 15-20 minutes), mainly due to its evaporation from the metal bath. It involves the necessity of repeated treatments of modification, which, in the case of continuous production, seems to be unacceptable.

As an alternative, in such a case, continuous electrolysis of sodium salts can be applied and this takes place directly in the metal bath [9-11]. The basic condition that must be met to enable the process is usage of a solid electrolyte, providing an ionic conductivity and preserving the stable stage of aggregation at temperatures of $873 \div 1073 \mathrm{~K}$.

Such electrolytes consist of a durable, semi-crystalline material based on beta-alumina, conducting ions of sodium [12-14] that arise as a result of dissociation and electrolysis, which, when in contact with liquid alloy, are transformed into an atomic state, modifying the alloy.

The beta-alumina, carrying ions of sodium is accessible commercially in the form of thin-wall pipes, rods and plates. The main areas of its application are cells of highly efficient batteries based on the solid electrolyte [15-18] and sodium sensors [19].

The objective of the present work is an attempt to use sodium salt electrolysis for the modification of near-eutectic aluminum-silicon alloy.

\footnotetext{
UNIVERSITY OF BIELSKO-BIAŁA, DEPARTMENT OF PRODUCTION ENGINEERING AND AUTOMATION, 2 WILLOWA STR., 43-309 BIELSKO-BIAŁA, POLAND

Corresponding author: jpezda@ath.bielsko.pl
} 


\section{Experimental procedure}

The EN AC-44200 (EN AC-AlSi12) alloy is a commercial alloy belonging to a group of near-eutectic alloys used for the production of complicated castings. The investigated alloy was melted in a ceramic crucible in an electric resistance furnace.

The test stand, with a scheme shown in the (Fig. 1), was used in the tests.

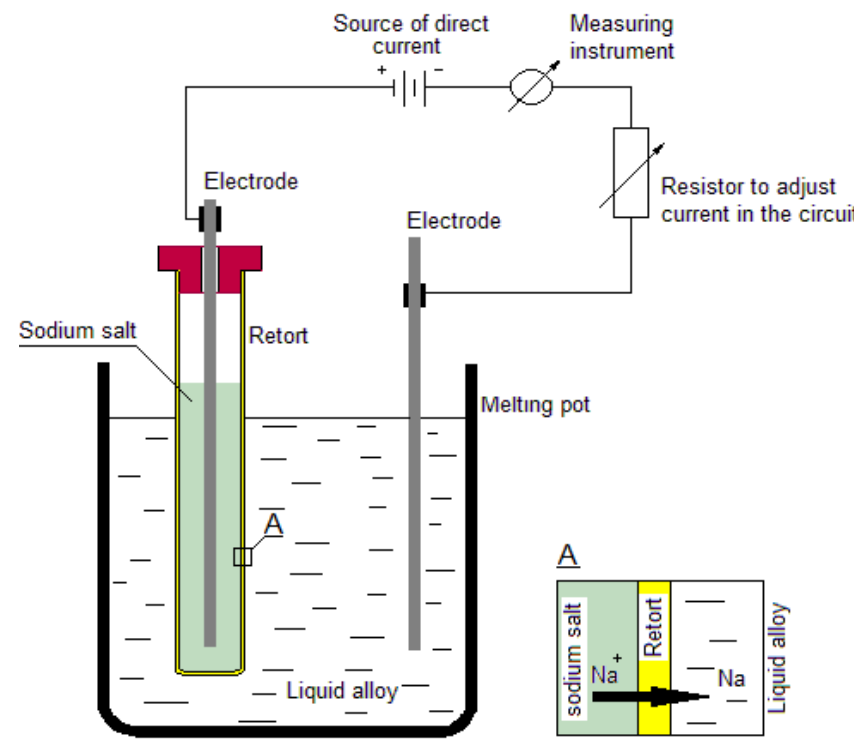

Fig. 1. Scheme of the test stand

The sodium salt poured into a storage bin (retort) was produced from material based on beta-alumina, as a result of the applied DC voltage, undergoes dissociation followed by electrolysis. Two electrodes directly assure the flow of electric current - the first is directly immersed in a liquid salt (anode), the second one in a liquid alloy (cathode). The retort, prior to its usage, was stabilized (annealed) at a temperature of $973 \mathrm{~K}$ and cooled down in the furnace. A one-side closed retort, produced from beta-alumina, stabilized by zirconium (type B2), which is produced by English company Ionotec Ltd., was used in the course of the tests.

In the tests, salts comprising the following chemical compounds: $\mathrm{NaCl}, \mathrm{NaNO}_{3}$ and $\mathrm{Na}_{2} \mathrm{CO}_{3}$ were used as material for the anode (source of sodium ions).

In order to initialize heating of the retort filled with sodium to a temperature of about $573-623 \mathrm{~K}$, and the same to restrict a possibility of cracking of the retort when immersed in liquid alloy, after filling the retort with salt and installation of the supply system, the whole set was placed for a few minutes directly above the level of the metal superheated to a temperature of $953 \mathrm{~K}$. After immersing the retort filled with the salt in the liquid alloy, none of the operations was performed for a few minutes, because the salt in the retort was not melted yet. Only after obtaining the liquid state of the salt, one closed the electric circuit, setting the current intensity at a level of $4.5 \div 5,0 \mathrm{~A}$.

After immersing the retort made from the beta-alumina, the electric current did not flow during the first few minutes in the liquid alloy and after closing the electric circuit. It should be expected, because the sodium salt in the retort was not melted yet, and the process of its dissociation and electrolysis did not occur.

The duration of the experiment was connected with the quantity of the melted material ( $25 \mathrm{~kg}$ of the alloy), from which test pieces were poured. Castings of the test pieces were produced every 10 minutes by pouring the metal mould. Three test pieces to check the tensile strength Rm were poured for each experiment. The tensile strength Rm tests were performed on the ZD-20 testing machine according to the PN-EN ISO 68921:2010P standard. Photomicrographs of microstructures were made with the use of the Neophot 32 microscope and a MultiScan computerized system for photo analysis. No cracks of the retort were observed, which suggests a possibility of its reusability.

\section{Results and discussion}

In the (Fig. 2) is presented a change of the tensile strength Rm during the course of continuous modification of the investigated alloy through the use of multicomponent electrolysis of sodium salt.

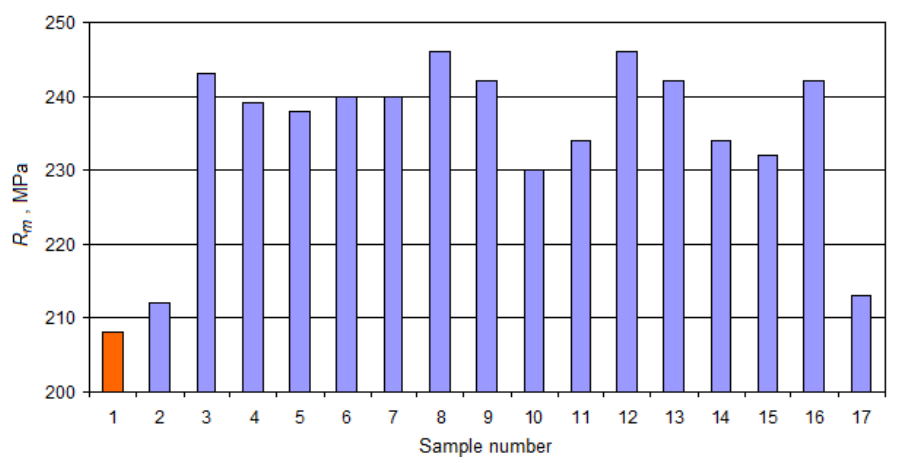

Fig. 2. Course of tensile strength change during modification of the alloy

The test piece marked as No. 1 (Fig. 2) corresponds to refined (initial) alloy. The test piece marked as No. 1 corresponds to refined (initial) alloy. Numbering of the test pieces corresponds to a sequence of production of castings of the test pieces with a 600 second ( 10 minutes) pause between successive pourings of metal moulds. 300 seconds ( 5 minutes) after immersing the retort, the ammeter indicated the value of the electric current at a level of 4.5 A, which indicated the beginning of electrolysis and dissociation, i.e. melting of the salt in the retort. After 600 seconds (10 minutes), the value of the electric current amounted to $4.5 \mathrm{~A}$ (pouring of the test piece No. 2, (Fig. 2)), during the successive 10800 seconds (180 minutes), one recorded a constant value of the electric current, oscillating between $4.5 \div 4.7 \mathrm{~A}$.

The modification process occurred for 11400 seconds (190 minutes). After 1800 seconds ( 30 minutes) from the beginning of the modification, one noticed a considerable improvement of the tensile strength Rm (test piece No.4, (Fig. 2)), which amounted to $243 \mathrm{MPa}$. The measured tensile strength showed a certain stabilization for a longer period of time. A drop of the tensile 
strength was observed after 11400 seconds (190 minutes), which resulted from a deficiency of the salt in the retort. Thus, in the aspect of the obtained tensile strength $\mathrm{Rm}$ in the course of the experiment, the assessment of modification effect is positive. The correctly performed process of modification of near-eutectic silumin is characterized by a change of its structure (refinement of eutectic silicone). To confirm a change of the structure, one performed photomicrographs of metallographic structures for the initial alloy and the alloy after 1200 seconds (20 minutes) and 9600 seconds (160 minutes) after onset of the electrolysis process of the sodium salt.
In the (Fig. 3) are presented photomicrographs of microstructures of the investigated alloy before commencing electrolysis of the sodium salt.

Microstructure of the initial alloy before starting the electrolysis can be characterized by distinct precipitations of phase $\beta$ in the form of lamellar silicone, which are present in unmodified alloys.

In the next figures are shown microstructures of the alloy after 20 minutes (Fig. 4a,b) and after 160 minutes (Fig. 4c,d) of the electrolysis process.
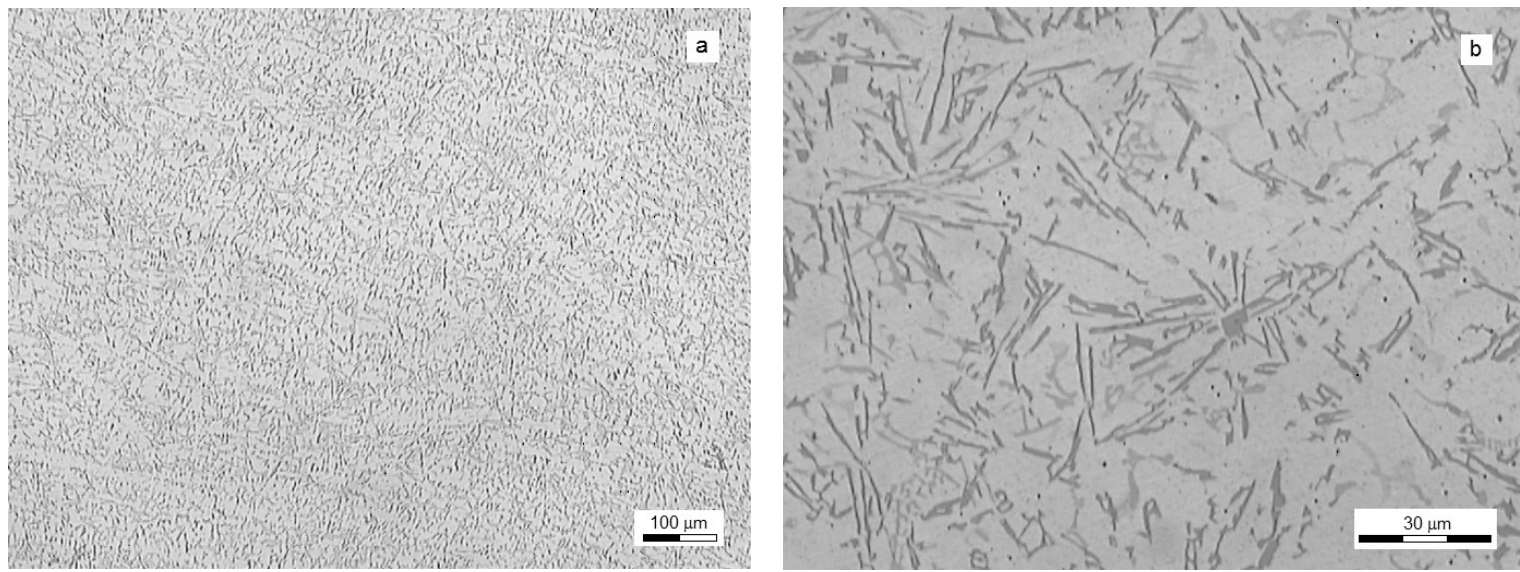

Fig. 3. Microstructure of the EN AC-44200 after refinement (initial alloy)
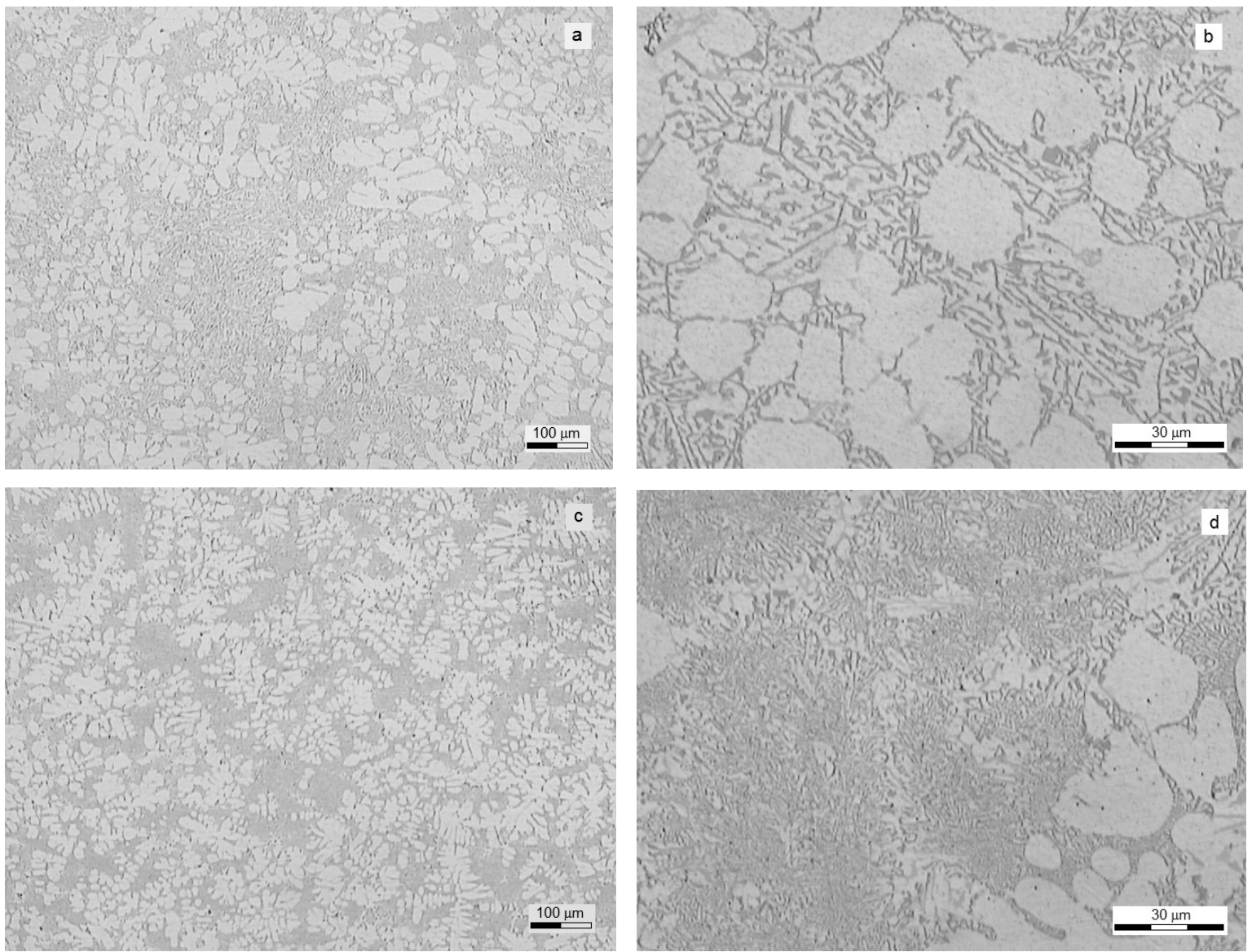

Fig. 4. Microstructures of the EN AC-44200 alloy after 20 minutes of electrolysis (a,b) and 160 minutes of electrolysis (c,d) 
In the case of the test piece poured after 20 minutes (Fig. 4b) it can be seen partially modified as silicone in the eutectic mixture $\alpha+\beta$, being the result of the commenced process of the modification. The microstructure of the alloy presented in the (Fig. 4d) is characterized by dendritic precipitations of phase $\alpha-\mathrm{Al}$ and the modified eutectic silicone. This type of the microstructure is characteristic of the alloy, which underwent treatment of the modification.

\section{Conclusion}

The obtained results of the tests concerning the tensile strength $\mathrm{Rm}$ and analysis of the microstructure have confirmed the obtainment of the modification effect, which can be maintained permanently during the electrolysis process of the sodium salt. It points at the conductivity of sodium ions by the solid electrolyte under physico-chemical conditions present during the modification of the EN AC-44200 alloy. The investigated ternary salt, with its simple chemical composition, fulfills the requirements concerning its long-lasting action. There exists a need of further investigations aimed at the optimization of the electrolysis parameters and composition of the sodium salt in the aspect of the process stabilization to obtain the required mechanical properties of near-eutectic silumins.

\section{Acknowledgements}

The present work was performed within framework of the Research Project No. 3 T08B 06329

\section{REFERENCES}

[1] J.R. Davis, ASM Specialty Handbook: Aluminum and Aluminum Alloys, 1993 ASM International Materials Park, Ohio.

[2] A.K. Dahle, K. Nogita, S.D. Mc Donald, C. Dinnis, L. Lu, Mater. Sci. Eng. A. 413-414, 243-248 (2005).

[3] S. Hegde, K.N. Prabhu, J. Mater. Sci. 43 (9), 3009-3027 (2008).

[4] M.M. Makhlouf, H.V. Guthy, J. Light Met. 2 (1), 199-218 (2001).

[5] Z. Poniewierski, Krystalizacja, struktura i właściwości siluminów, WNT Warszawa 1989.

[6] M.D. Hanna, S.Z. Lu, A. Hellawell, Metall. Mater. Trans. A. 15A, 459-469 (1984).

[7] B. Suárez-Pena, J. Asensio-Lozano, Scripta Mater. 54 (9), 15431548 (2006).

[8] N. Fatahalla, M. Hafiz, M. Abdulkhalek, J. Mater. Sci. 34 (14), 3555-3564 (1999).

[9] A. Białobrzeski, P. Dudek, A. Fajkiel, W. Leśniewski, Archives of Foundry 6 (18), 97-103 (2006).

[10] J. Pezda, Metalurgija 53 (1), 55-58 (2014).

[11] A. Białobrzeski, Archives of Foundry Engineering 7 (1), 53-56 (2007).

[12] N. Weber, Energy Conversion 14, 1-8 (1974).

[13] Y.F.Y. Yao, J.T. Kummer, J. Inorg. Nucl. Chem. 29 (9), 2453-2466 (1967).

[14] M.S. Whittingham, R.A. Huggins, J. Chem. Phys. 54 (1), 414-416 (1971).

[15] X.C. Lu, G.G. Xia, J.P. Lemmon, Z.G. Yang, J. Power Sourc. 195 (9), 2431-2442 (2010).

[16] P.T. Moseley, R.J. Bones, D.A. Teagle, B.A. Bellamy, R.W.M. Hawes, J. Electrochem. Soc. 136 (5), 1361-1368 (1989).

[17] D.J. Fray, R.J. Brisley, Metall. Mater. Trans. B. 14 (3), 435-440 (1983).

[18] Z. Wen, J. Cao, Z. Gu, X. Xu, F. Zhang, Z. Lin, Solid State Ionics. 179 (27-32), 1697-1701 (2008).

[19] G. Doughty, D.J. Fray, C. Van Der Poorten, J. DeKeyser, Solid State Ionics. 86-88 (1), 193-196 (1996). 